\title{
Sex Differences in Aggressivity and the Effects of Social Isolation in the Anabantoid Fish, Macropodus opercularis ${ }^{1}$
}

\author{
ROGER E. DAVIS, COLIN HARRIS, ${ }^{2}$ and JESSIE SHELBY \\ Mental Health Research Institute and \\ Neurosciences Laboratory, The University of Michigan, \\ Ann Arbor, Michigan 48104
}

\begin{abstract}
The aggressivity of adult males and females was evaluated by measuring (1) the frequency of aggressive displays that individuals made toward a mirror image stimulus following varying periods of social isolation, (2) the display frequency in brief, unisexual and bisexual bouts with live opponents, and (3) the reinforcing effects of mirror image stimulation on performance of an approach response. Isolation up to seven days increased aggressivity in both sexes. Males performed lateral display toward a mirror image or a live conspecific more frequently than females. Mirror image stimulation also was a stronger positive reinforcer in males than in females.
\end{abstract}

Investigations in various anabantoid fishes show that aggressive behavior in males can readily be elicited by visual presentation of another male (Forselius, 1957; Thompson, 1963, 1969; Piccilio, 1964; Simpson, 1968). Males repeatedly approach a place where they can see a mirror image stimulus, another male, or a colored model, suggesting that such stimuli are reinforcing to males. Thompson (1963) demonstrated that adult male Betta splendens, the Siamese fighting fish, repeatedly perform an arbitrary instrumental response which results in the presentation of a mirror image stimulus or a moving or stationary model. The response rate covaries with the effectiveness of the particular stimulus in eliciting aggressive behavior (Thompson, 1963) and with the individual's recent social agonistic experience with other males (Baenninger, 1970). Adult male Macropodus opercularis, the paradise fish, a relative of $B$. splendens in the subfamily Macropodinae [family Belontidae (Liem, 1963)], also react aggressively to mirror image stimuli (Forselius, 1957) and such stimuli are potent, positive reinforcers in males (Melvin and Anson, 1970). Similar results have been reported in other fishes. Aggression-eliciting stimuli can reinforce instrumental responses in male Gasterosteus aculeatus,

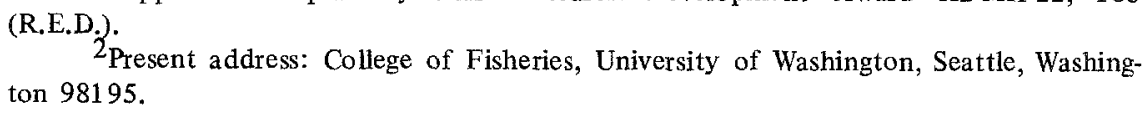

${ }^{2}$ Present address: College of Fisheries, University of Washington, Seattle, Washington 98195 . 
the three-spined stickleback (Sevenster, 1968) and in immature Microspathodon chrysurus, the damsel fish (Rasa, 1971). Comparisons between mature females and males have not been made in fishes. In seminatural settings in the laboratory, female $M$. opercularis and $B$. splendens are not obviously more or less aggressive than males. Females display toward tank mates of both sexes, chase, bite, and fight as males do (Braddock and Braddock, 1955; Forselius, 1957; Miller and Miller, 1971). Appetitive effects of social agonistic encounters, however, have not been demonstrated in females. In these experiments in $M$. opercularis, the rate at which adult females performed aggressive displays to mirror image stimuli and to a live conspecific was compared with that of adult males. In addition, sex differences in the effectiveness of mirror image stimuli as reinforcement for an instrumental response was investigated.

\section{EXPERIMENT 1}

The first experiment was done to determine whether males and females show different frequencies of aggressive displays and approach responses to an avoidable mirror image stimulus. In established, bisexual groups of $M$. opercularis displays are typically brief, but frequent elements of the daily activities of males and females. A fish that is removed from such a tank and immediately paired with a conspecific in a neutral tank or given a view of its own image in a mirror or may not react aggressively. Individuals may freeze for many minutes, moving only to rise to the surface to breathe, or withdraw and avoid the stimulus. An aggressive reaction is frequently obtained, however, when the fish is previously kept in a separate tank out of sight of other fish for several days. Social isolation results in increased aggressivity in various animals (Ulrich, 1966; Lagerspaetz and Lagerspaetz, 1971; Krsick and Janku, 1969) including fishes, namely $M$. chysurus (Rasa, 1971), Cichlasoma nigrofaciatum, the convict cichlid (Gallagher, Herz, Peeke, 1972), Macropodus cupanus, the Indian paradise fish ( $\mathrm{Pal}, 1968)$, and M. opercularis, (Ward, 1967). The increase in aggressivity in isolated fish has not been extensively studied. To determine whether isolation affects the sexes differently, males and females were isolated for varying periods prior to the mirror stimulation test.

\section{Method}

Subjects. M. opercularis adults obtained from Gossington Tropical Fisheries, Del Ray Beach, Fla, were kept in 75 and 190-liter community tanks in bisexual lots of 25-150 individuals. They were in the laboratory for 2 to 4 weeks prior to experiments. Fish were fed Tetramin Staple Food or frozen brine shrimp one to three times daily and occasionally mosquito larvae. The 
water was continuously filtered and kept at $24-26^{\circ} \mathrm{C}$. The tanks were brightly illuminated with day light fluorescent light for $14 \mathrm{hr}$ each day. Female subjects ranged from 3.0 to $4.5 \mathrm{~g}$ body wt and 3.5 to $5.0 \mathrm{~cm}$ body length; males ranged from 3.0 to $6.5 \mathrm{~g}$ and 4.0 to $6.0 \mathrm{~cm}$. Sex was determined by external morphology and, where a question remained following an experiment, gonad dissection. The adult male has longer medial fins than the female, in relation to body length (Forselius, 1957; Ward, 1967). The male also has a wider mouth and more erect, urogenital papillae than the female.

Isolation tank. The isolation tank was a 9.5-liter Metaframe aquarium, $30 \times 15 \times 20 \mathrm{~cm}$ high with a black slate bottom and glass walls in a stainless steel frame. The side walls facing adjoining tanks were covered with tan cardboard to block the view of other fish. A small air-driven water filter sat in a rear corner of the tank. The tightly covered tank was only partially filled, to a depth of $15 \mathrm{~cm}$, to prevent escape. Isolated fish could see some part of the laboratory, including human traffic, through the front of the tank.

Mirror stimulus tank. The stimulus mirror was presented in a neutral tank $40 \times 15 \times 20 \mathrm{~cm}$ high in a separate room. The $40 \mathrm{~cm}$ walls of the tank were clear glass. The bottom and the $15 \mathrm{~cm}$ walls were nonreflecting, black Plexiglas. The tank was filled to $16 \mathrm{~cm}$ with fresh, dechlorinated, $25-26^{\circ} \mathrm{C}$ tapwater which flowed through the tank at $150 \mathrm{ml} / \mathrm{min}$. To measure swimming activity, a grid was drawn on the $40 \mathrm{~cm}$ glass walls. The grid consisted of three vertical lines dividing the tank into four $10 \mathrm{~cm}$ wide columns and one horizontal line midway between the water surface and the tank bottom. The water was illuminated by two $75 \mathrm{~W}$ bulbs $30 \mathrm{~cm}$ above the tank. A two-way mirror placed $20 \mathrm{~cm}$ in front of the tank deflected the fish's image upward, yet allowed the investigator to see through from the darkened room. A $10 \times 16 \mathrm{~cm}$ glass stimulus mirror was attached on the outside of the rear wall on the tank in the left most column of the activity grid. The fish could see its own image only when in the leftmost $10 \mathrm{~cm}$ of the tank.

\section{Procedure}

Ten males and ten females were taken from community tanks and placed in separate isolation tanks for either $4 \mathrm{hrs} .1,4$, and 7 days prior to administration of a $10 \mathrm{~min}$ mirror reaction test. A fifth group of males and females which were not isolated were removed from the community tanks and immediately administered the mirror test. The fish were individually transferred between the isolation tank and the mirror test tank. The 10 min test period was started when the fish approached the mirror for the first time. The frequency of approach, lateral and frontal displays (Forselius, 1957; Miller, 1971) toward the mirror, and air gulping was registered with a keyboard in conjunction with an Esterline Angus event recorder. Approach consisted of moving to a position in front of the mirror from the outside the $10 \mathrm{~cm}$ wide mirror zone. Lateral display (LD) was recorded when a fish erected its medial 
fins, the caudal, anal, and dorsal, broadside to the mirror. Frontal display (FD) was defined as spreading the opercles while the fish faced its image. Air gulp was recorded each time the fish touched the water surface with its snout and gulped air. Activity was measured as the number of times that the fish crossed the horizontal and vertical grid lines with its head.

\section{Results}

The results are summarized in Table 1. A two-way analysis of variance on Sex $X$ Isolation Period was carried out for each response variable. The frequencies of LD and FD showed significant Isolation effects $(F=15.42$ and 17.46, respectively, $d f=1,9, P<.01$ ) but only $L D$ showed a Sex effect $(F=19.18, d f=1,9, \quad P<.01)$. Approach, Air Gulp, and Activity varied nonlinearly with 1solation Period $(F=4.02,3.89,14.72$, respectively, $d f=4,36, P<.01)$ and showed no significant Sex effect. One-way analyses (Table 1) confirm that though females showed fewer LD than males, LD frequency increased with Isolation in both sexes. Approach varied with Air Gulp and Activity in both sexes (Table 2). LD and FD covaried with Approach in males and females but not with Activity, in either sex, or with Air Gulp in males. In females, LD and FD varied inversely with Air Gulp.

\section{EXPERIMENT 2}

Males showed a higher LD rate in the mirror stimulus test than did females. The second experiment was to determine whether the sexes differ in TABLE 1

Frequency of Responses of Male and Females to Mirror Image Stimulation Following Isolation

\begin{tabular}{|c|c|c|c|c|c|c|c|}
\hline \multirow[t]{2}{*}{ Response } & \multirow[t]{2}{*}{ Sex } & \multicolumn{5}{|c|}{ Period of isolation } & \multirow[t]{2}{*}{$P$} \\
\hline & & $\mathrm{Oh}$ & $4 h$ & $1 d$ & $4 d$ & $7 d$ & \\
\hline \multirow[t]{2}{*}{$\mathrm{LD}$} & $\mathrm{F}$ & 0 & 0.6 & 1.0 & 12.3 & 9.0 & $.004^{a}$ \\
\hline & $\mathbf{M}$ & 0 & 4.0 & 11.7 & 17.3 & 25.0 & .001 \\
\hline \multirow[t]{2}{*}{ FD } & $\mathrm{F}$ & 4.5 & 5.6 & 14.1 & 24.0 & 30.1 & .001 \\
\hline & $\mathbf{M}$ & 3.8 & 9.9 & 9.8 & 22.7 & 24.5 & .001 \\
\hline \multirow[t]{2}{*}{ Approach } & $\mathrm{F}$ & 15.7 & 22.3 & 17.5 & 16.0 & 17.3 & .5 \\
\hline & $\mathrm{M}$ & 13.8 & 23.1 & 17.5 & 13.3 & 24.5 & .002 \\
\hline \multirow[t]{2}{*}{ Air gulp } & $\dot{F}$ & 15.2 & 27.4 & 21.2 & 8.3 & 11.1 & .001 \\
\hline & M & 13.8 & 24.8 & 16.8 & 7.2 & 23.9 & .001 \\
\hline \multirow[t]{2}{*}{ Activity } & $\mathrm{F}$ & 112 & 134 & 162 & 80 & 93 & .04 \\
\hline & M & 152 & 131 & 102 & 68 & 110 & .02 \\
\hline
\end{tabular}


TABLE 2

Correlations between Behavioral Variables for Males and for Females in Experiment 1

\begin{tabular}{|c|c|c|c|c|c|c|c|c|}
\hline \multirow[b]{3}{*}{ Correlate } & \multicolumn{6}{|c|}{ Behavior } & \multirow{2}{*}{\multicolumn{2}{|c|}{ Activity }} \\
\hline & \multicolumn{2}{|c|}{ Approach } & \multicolumn{2}{|c|}{ LD } & \multicolumn{2}{|c|}{ FD } & & \\
\hline & $\mathrm{M}$ & $\mathrm{F}$ & $\mathbf{M}$ & $\mathrm{F}$ & M & $\mathrm{F}$ & $\mathrm{M}$ & F \\
\hline $\mathrm{LD}$ & $.338^{a}$ & $\mathrm{Ns}$ & & & & & & \\
\hline FD & .387 & Ns & .760 & .472 & & & & \\
\hline $\mathrm{ACT}$ & .462 & .633 & Ns & $\mathrm{Ns}$ & Ns & $\mathrm{Ns}$ & & \\
\hline $\mathrm{AG}$ & .600 & .486 & Ns & -.352 & Ns & -.359 & .460 & .489 \\
\hline
\end{tabular}

${ }^{a}$ Critical values of $\mathrm{r}$ for $P<.05$ and $P<.01$ are 0.279 and $0.361 ; d f=48$.

the rate and duration of threat displays in an encounter with a live opponent. If females are less positively reinforced by visual stimuli than males, females should display less than males in a brief encounter. Interfemale encounters should result in fewer and possibly shorter displays than intermale encounters.

\section{Procedure}

Twelve males and females that were previously isolated for 7-10 days were randomly paired with each other in ten trials, five unisexual and five bisexual, in the neutral test tank. Opponents were alternated by sex in successive trials. The interval between trials varied between 2 and 3 days. A trial lasted 5 min starting when the two fish were poured into the tank. The trial was limited to $5 \mathrm{~min}$ as, in our experience, most individuals engage in threat displays within that time and attacks which could produce injury and lasting aversive responses begin later. The males weighed $3.3-5.8 \mathrm{~g}$ and were $4.3-5.0 \mathrm{~cm}$ in body length, the males weighted $4.1-5.5 \mathrm{~g}$ and were $4.9-5.5 \mathrm{~cm}$ long.

The frequency of $\mathrm{LD}$ and FD, and of Quiver was recorded for both fish in each encounter. Responses were registered with a keyboard as in Expt. 1. The charts speed was $3.8 \mathrm{~cm} / \mathrm{min}$ and durations were measured to the nearest second. LD and FD were defined as in Expt. 1. In direct encounters between fish, in contrast to a fish and its mirror image, LD occurs at various angles to the opponent including fish arranged head-to-tail, or antiparallel. The antiparallel position is typical in $M$ opercularis and it occurs in both sexes. In this experiment, LD was recorded when the subject presented its broadside in front of, parallel, or antiparallel to the opponent. Quiver is a rapid shimmer, or vibration, of the entire body accompanying which the fish may descend in the water (Forselius, 1957; Miller and Miller, 1971). Quiver is performed at the end of intense, lateral displays in the antiparallel position (Southwick and Ward, 1968) by one or both members of the pair. 
TABLE 3

Frequency of Responses by Males and Females to Opponents of the Same and of the Opposite Sex

\begin{tabular}{cccc}
\hline & $\begin{array}{c}\text { Subject } \\
\text { Response }\end{array}$ & Opponent sex \\
\hline LD & Sex & Same & Opposite \\
\multirow{2}{*}{ FD } & F & $16.9^{a}$ & 15.2 \\
& M & 31.8 & 21.5 \\
Quiver & F & 11.8 & 10.4 \\
& M & 12.4 & 12.2 \\
& F & 3.3 & 4.0 \\
\hline
\end{tabular}

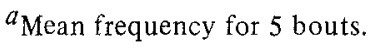

Results

Males showed a higher frequency of LD in unisexual and in bisexual trials than did females (Table 3). A two-way analysis of variance indicates a significant effect of Subject Sex, Opponent Sex, and their interaction $(F=11.00,18.36$, and 9.77, respectively, $d f=1,11, P<.01)$. Males performed LD more frequently in unisexual than bisexual trials (Students $t$ test: $t=4.25$, $P<.001)$ while females responded similarly to both sexes $(t=1.29, P<.22)$.

LD frequency and duration were highly correlated for males and for females in trials with opponents of either $\operatorname{sex}(P<.01)$. The mean duration of $L D$ in a trial was greater for males than for females (Table 4). A two-way analysis of variance of LD duration reveals significant Subject Sex and Opponent Sex effects, and interaction $(F=13.30,16.68$, and 17.26, respectively, $d f=1,11, P<.01)$. The Opponent Sex effect is significant for males

TABLE 4

Duration of LD and FD by Males and Females to Opponents of the Same and of the Opposite Sex in Experiment 2

\begin{tabular}{cccc}
\hline & & \multicolumn{2}{c}{ Opponent sex } \\
Response & $\begin{array}{c}\text { Subject } \\
\text { sex }\end{array}$ & Same & Opposite \\
\hline LD & F & $27.7^{a}$ & 23.2 \\
FD & M & 61.8 & 42.6 \\
& F & 15.8 & 12.2 \\
M & 13.6 & 16.8 \\
\hline
\end{tabular}

${ }^{a}$ Mean seconds for 5 bouts. 
$(t=4.48, P<.01)$ but not for females $(t=2.03, P<.07)$. The average duration of LD in a trial was longer for males than for females $(F=13.58, d f=1,11$, $P<.001)$ but it did not vary with the sex of the opponent $(F<1)$. Male LD averaged 1.90 and $1.94 \mathrm{sec}$ in unisexual and bisexual trials, female LD averaged 1.63 and $1.61 \mathrm{sec}$, respectively.

The sexes also differed in Quiver rate (Table 3). A two-way analysis of variance revealed a significant effect of Subject Sex, Opponent Sex, and their interaction $(F=16.42,17.92,20.43$, respectively, $d f=1,11, P<.01)$. Intermale trials resulted in several times as many Quiver responses as the interfemale trials $(t=5.07, P<.01)$. In bisexual trials males and females showed equivalent, low rates of Quiver. The opponent Sex effect was significant for males $(t=4.51, P<.01)$ but not for females.

The FD rate was similar in males and females. The frequency and duration of FD did not vary significantly with Subject Sex or Opponent Sex or Opponent Sex (Table 3 and 4). Both sexes showed fewer FD than LD $(P<.001)$.

\section{Individual Variation in Display Frequency}

Correlation coefficients for LD and FD frequency, and for the total of LD plus FD in successive trials were calculated. Few of the correlations were significant for either sex, and the coefficients showed no systematic patterns with repeated unisexual or bisexual trials. A single encounter was thus not a reliable estimate of an individual's performance in subsequent encounters. Averaging data for several trials, however, produced highly reliable estimates of an individual's relative level of responding. For example, the 12 males and females ranked according to their mean total displays/trial in the five unisexual trials showed similar ranking in the five bisexual trials (Fig. 1). For

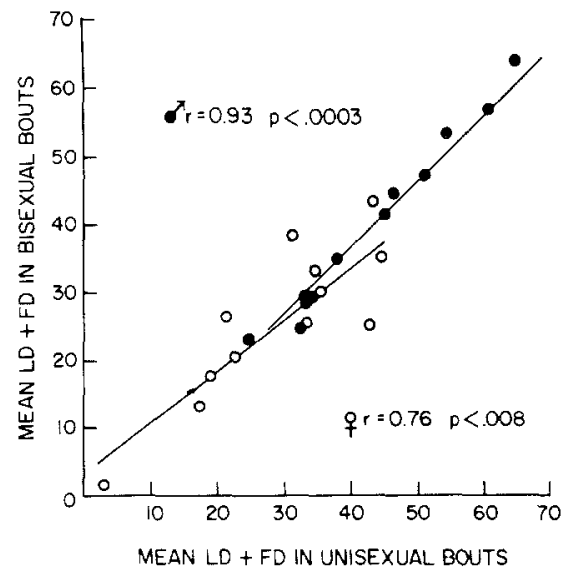

Fig. 1. Correlation of mean total displays, $L D+F D$, in 5 unisexual and 5 bisexual bouts for individual males $(\bullet)$ and females $(c)$. 
males, LD in unisexual and bisexual trials was more highly correlated $(r=.85$, $P<.002)$ than FD $(r=.69, P<.03)$, whereas the reverse held for females (FD, $r=.94, P<.000 ; \mathrm{LD}, r=.73, P<.01$ ). The data in Fig. 1 show that the range of the average response frequency among the females was less than that among the males but that high and low responders are represented in both groups.

\section{EXPERIMENT 3}

The preceding experiments showed that males perform LD at a higher rate than females do. The sex difference in response rate suggested that brief social encounters might be stronger reinforcers in males than in females. In this experiment we investigated the reinforcing effects of a mirror image stimulus by making access to the stimulus contingent on swimming into one of two tunnels from a lighted, seminatural living space. The alternate tunnel contained no mirror. The living space was enriched with stimuli to compete with the mirror stimulus, to provide the subject with response opportunities other than approaching the mirror in an arm of the tank. We anticipated from the results of Melvin and Anson (1970) that the mirror image stimulus would result in increased visits to the mirror arm by males. We sought to confirm their results in males and to determine whether females react appetitively to their mirror image.

\section{Method}

The experimental tank was $40 \times 40 \times 20 \mathrm{~cm}$ deep and it had two small side arms. The tank was in a chamber with a one-way viewing screen in front. The front and rear wall of the tank were clear glass, the side walls were opaque Plexiglas. The tank was filled with $16 \mathrm{~cm}$ of water at $25-26^{\circ} \mathrm{C}$. A gravel bottom, flowering plants, a clay brick with holes, a water heater, and filter provided numerous crevices for a fish to investigate. In addition, a separate tank, $40 \times 15 \times 20 \mathrm{~cm}$ deep, was placed behind the rear wall of the experimental tank to hold several immature amazon mollies, Poecilia formosa, as dither fish, or moving, nonconspecific stimuli to enrich the environment and distract the otherwise isolated subject. Each tank arm consisted of an $18 \mathrm{~cm}$ long, L-shaped, darkened tunnel with a $12 \mathrm{~cm}$ long lighted compartment at the end. The tunnel was approximately $3 \mathrm{~cm}$ wide and $3 \mathrm{~cm}$ high; the lighted section was $5 \times 5 \mathrm{~cm}$. The two arms extended from opposite sides of the tank with openings just below the surface of the water, and at no point in an arm could a fish contact the air. Fish had to return to the central section of the tank to breath at the surface. Moderately active adults replenish air in the suprabrancial respiratory cavity once every $50-70 \mathrm{sec}$ at $25-26^{\circ} \mathrm{C}$. Fish entered an arm through a $90^{\circ}$ bend of plastic pipe, $3.5 \mathrm{~cm}$ i.d., one end of 
which was attached to the tank wall. The open end of the pipe was thus perpendicular to the tank wall, as in the tank deseribed by Rasa (1971). The pipe bend led the fish to a straight section of the tunnel which contained two photoelectric switch beams $7 \mathrm{~cm}$ apart. A fish could not occlude both beams at once. The order in which the switches operated thus indicated when fish entered and exited the distal most section of the arm. Switch operations were automatically registered with a BRS-Foringer Digibit system on an ink trace event recorder and on paper tape. The frequency and the duration of entries, measured to the nearest $0.2 \mathrm{sec}$, was compiled by digital computer from the paper tape record. The tunnel opened through a $2.5 \mathrm{~cm}$ hole into the terminal, lighted mirror compartment. The far end and the bottom of the compartment were opaque; the front and rear walls were clear. The fish could see out the front wall toward the observer's screen, out the rear into a vacant section of the tank, and upward through a clear plastic cover on the water surface. During the period of mirror stimulation, a $5 \times 12 \mathrm{~cm}$ glass mirror was placed behind the rear wall of the compartment of one arm.

\section{Procedure}

Ten males and ten females isolated for 7-10 days were placed individually in the experimental tank for a $24 \mathrm{hr}$ period starting several hours prior to the onset of the daily, $10 \mathrm{hr}$ dark period. The males weighed $4.0-6.2 \mathrm{~g}$ and were $5.0-5.9 \mathrm{~cm}$ long, the females weighed $3.5-5.7 \mathrm{~g}$ and were $4.2-5.3 \mathrm{~cm}$ long. The subject's movement in and out of the arms were registered with the event recorder until the following morning. Recording on paper tape was started at about $0900 \mathrm{hr}$ to obtain quantitative data on visits in the two arms during a $2 \mathrm{hr}$, prestimulus period. The chamber was then opened and the stimulus mirror was placed in the arm that the fish had visited least. Conditions in the other arm were unchanged. When the fish entered the arm and encountered the mirror, recording was continued for $2 \mathrm{hr}$. Following the $2 \mathrm{hr}$ stimulus period, at a time when the fish was in the central section of the tank, the observer opened the chamber and removed the mirror. A 2-hr poststimulus period was recorded starting when the fish first entered the arm from which the mirror had been removed.

\section{Results}

Males and females entered either one or both arms of the tank within several hours after being placed in the tank. Activity in the arms was uncommon in the dark period but it resumed shortly following the onset of light the following day. One fish, a male, entered only one of the two arms prior to presentation of the mirror. Fish seemed to be attracted to the arms, particularly the females, spending a disproportionate amount of time there in relation to the space. The two lighted compartments amounted to less than 
$2 \%$ of the total tank volume. During the $2 \mathrm{hr}$ prestimulus period females averaged $22 \mathrm{~min}(19 \%)$ and males $7 \mathrm{~min}(6 \%)$ in the arms. Females had stronger arm biases than males prior to the mirror stimulus presentation (Table 5).

\section{Mirror Image Reinforcement}

A four-way analysis of variance of $\operatorname{Sex} X$ Period $X$ Arm $X$ Subject revealed significant Sex interactions for frequency and duration of approaches to the arms (Table 5). The Sex $\times$ Period interaction was significant for both frequency and duration ( $F=6.81$ and 13.36, respectively, $d f=3,36, P<.01)$. The Sex $\times$ Arm interaction also was significant for frequency and duration $(F=25.95$ and 10.93 , respectively, $d f=1,18, P<.01$ ). Sex alone, however, had no significant effects. The causes of the significant Sex interactions are evident in the mean frequency and duration data in Table 5. Females showed less change in responding between the three 2 -hr periods and smaller differences in responses to the two arms than males did.

A three-way analysis of variance of Period $X$ Arm $\times$ Subject further elucidates the difference in responding between the sexes. Male response frequency showed a large Period effect $(F=64.12, d f=2,18, P<.01)$, Arm effect $(F=83.27, d f=1 / 8, P<.01)$, and the Period $\times$ Arm interaction was also substantial $(F=51.28, d f=2.18, P<.01)$. Most of the Period effect was in the mirror stimulus arm. In females, on the other hand, the differences between response frequency in the various periods and in the two arms were not significant. Females showed only slightly more subject variation $(F=6.02$, $d f=9,18, P<.01)$ than males $(F=4.67, d f=9,18, P<.01)$.

\section{TABLE 5}

The Mean Frequency and Duration of Approach Responses in the Mirror and No Mirror Arm Before, During and Following

Presentation of the Mirror Stimulus

\begin{tabular}{|c|c|c|c|c|c|c|c|c|}
\hline \multirow{3}{*}{$\begin{array}{c}2-\mathrm{Hr} \\
\text { Period }\end{array}$} & \multicolumn{3}{|c|}{ Male } & & \multicolumn{4}{|c|}{ Female } \\
\hline & \multicolumn{2}{|c|}{ Frequency } & \multicolumn{2}{|c|}{ Duration $^{a}$} & \multicolumn{2}{|c|}{ Frequency } & \multicolumn{2}{|c|}{ Duration } \\
\hline & $\mathrm{S}+{ }^{b}$ & $S-$ & $\mathrm{S}+$ & S- & $\mathrm{S}+$ & S- & $S+$ & S- \\
\hline Prestimulus & 3.2 & 5.8 & 193 & 273 & 8.6 & 14.9 & 415 & 939 \\
\hline Stimulus & 30.2 & 7.2 & 2865 & 342 & 20.1 & 10.7 & 1804 & 416 \\
\hline Poststimulus & 13.6 & 5.6 & 1359 & 420 & 13.8 & 9.5 & 866 & 438 \\
\hline
\end{tabular}

${ }^{a}$ Seconds out of possible 7200 .

$b_{\text {Mirror stimulus arm. }}$ 
Male response duration showed a highly significant Period effect $(F=87.22, d f=2,18, P<.01)$, Arm effect $(F=176.98, d f=1,18, P<.01)$, and interaction $(F=79.82, d f=2,18, P<.01)$. Subject variation among the 10 males was nil. Females showed a strong Arm effect $(F=38.17, d f=1,18$, $P<.01)$ but the effect of Period was relatively weak $(F=4.98, d f=2,18$, $P<.05$, critical value $=3.55)$ as was the interaction $(F=8.18, d f=2,18$, $P<.01$, critical value $=6.01$ ). Response duration thus revealed some reinforcing effect of the mirror image stimulus in females.

\section{DISCUSSION}

These experiments indicate that in brief social encounters or in a situation where the individual can freely approach or avoid an encounter, males are more aggressive than females. Males perform threat displays at a higher frequency than females, and a mirror image is a stronger reinforcer in males than in females. The sex difference in incentive for mirror contact was clearly demonstrated in Expt. 3, in which the fish was provided with other response opportunities; males showed a 10 -fold increase in approach rate and a 15 -fold increase in duration; females showed only a 2 -fold increase in approach rate and a 4 -fold increase in response duration.

Males and females were seen to perform threat displays during approaches to the mirror compartment, in Expt. 3, but the responses were not systematically recorded. Our impression was that females displayed less frequently than males and tended to freeze before the mirror. As Simpson (1968) has proposed, independent measurement of unconditioned aggressive displays seems necessary to relate instrumental responding to aggressive motivation. Visual presentation of social stimuli which evoke no obvious aggressive responses has been shown to reinforce instrumental responses in various vertebrates including fish, Carassius auratus, the goldfish, which is commonly regarded as nonaggressive (Gallup and Hess, 1971). If an animal does not respond aggressively on presentation of the stimulus, it is obviously difficult to hold that aggressive motivation is solely responsible for the operant rate. Aggressive displays during mirror image reinforcement may decrease in frequency during prolonged sessions of operant responding in $B$. splendens (Baenninger, 1970). Other reinforcers may not consistently elicit the associated unconditioned responses. Fish responding for food may decrease feeding yet continue the instrumental response at a high rate (Rozin and Mayer, 1961; unreported observations in our laboratory).

In our experience, $M$. opercularis is highly motivated to patrol the living space and to inspect novel objects. Males and females will leap barriers. swim on their sides through shallow water over obstacles, and repeatedly enter airless labyrinths with no other apparent incentive than to explore or escape. 
The tendency to enter the tank arms during the $2 \mathrm{hr}$ prestimulus period (Table 5) reflects this behavioral trait. Behaviors other than those of threatening a conspecific may have reinforced the approach response in Expt. 3. We propose, however, that the motivation for approach is consistent with tendency to perform threat displays shown in Expts. 1 and 2. Taken together, the different measures suggest that masculinity and aggressivity are functionally related in this species as in other vertebrates (Collias, 1944).

Males performed LD more to male opponents than to females in the $5 \mathrm{~min}$ direct encounters. The higher frequency of Quiver in intermale trials seems consistent with this result. Quiver is the terminal act in the mutual lateral display (Southwick and Ward, 1957), or LD with opponents oriented head-to-tail (Forselius, 1957). Quiver would thus be expected to covary with the probability of the pattern that we label LD. Females perform mutual LD in a 5 min trial, with Quiver, but they do so less often than males.

The increase in aggressivity in isolated males and females was not accompanied by increases in air gulping or swimming in the test tank. We can offer no satisfactory explanation for the irregular variation in these activity measures. The isolates seemed more reactive to various stimuli during maintenance and handling and we anticipated that breathing and swimming in the $10 \mathrm{~min}$ mirror test would increase. Isolated male albino mice, for example, which show increased aggressivity are also more spontaneously active (Valzelli, 1969). Aggressivity in isolated mice develops slowly, over weeks (Krsiak and Janku, 1969; Lagerspaetz and Lagerspaetz, 1971) instead of hours to days as in $M$. opercularis (Table 1) and $M$. cupanus (Pal, 1968). Also, female mice typically are insensitive to isolation (Valzelli; 1969) though detecting aggressivity in females may depend on the nature of the opponent and the place of encounter (Edwards, 1968). Female $M$ opercularis are sensitive to isolation though apparently less so than males, based on rate of LD toward a mirror.

Increases in aggressivity in isolated animals can be interpreted as indicating that the threshold for social stimuli is lowered by social deprivation and that possibly the incentive for an encounter is correspondingly increased. Rasa (1971) showed that immature $M$. chrysurus in a seminatural aquarium continue to approach a place of prior encounter with a conspecific and that the duration of approaches increases over days following removal of the stimulus fish. The increase in the approach response under extinction does suggest that appetence for aggression varies spontaneously, or independently of prevailing external stimuli, as Rasa proposes. It is not clear, however, that social isolation affects social behavior processes specifically, or that only aggressive motivation is increased. Depriving a social creature of conspecific stimuli may have widespread emotional effects as thresholds to a variety of stimuli are lowered (Lagerspaetz and Lagerspaetz, 1971). Investigation of the effects of social isolation on various behavioral processes may reveal other differences in fish which are related to sex. 


\section{REFERENCES}

Baenninger, R. (1970). Visual reinforcement, habituation, and prior social experience of Siamese fighting fish. J. Comp. Physiol. Psychol. 71, 1-5.

Braddock, J. C. (1955). Aggressive behavior among females of the Siamese fighting fìsh, Betta splendens. Physiol. Zool. 28, 152-172.

Collias, N. E. (1944). Aggressive behavior among vertebrate animals. Physiol. Zool. 17, 83-123.

Edwards, D. A. (1969). Early androgen stimulation and aggressive behavior in male and female mice. Physiol. Behav. 4, 333-338.

Forselius, S. (1957). Studies of anabantoid fishes. Zool. Bidrag. Fran Uppsala 32, 93-597.

Gallagher, J. E., Herz, M. J., and Peeke, H. V. S. (1972). Habituation of aggression: The effects of visual social stimuli on behavior between adjacently territorial convict cichlids. Behav. Biol. 7, 359-368.

Gallup, G. G., and Hess, J. Y. (1971). Preference for mirror image stimulation in goldfish (Carassius auratus). Psychon. Sci. 23, 63-64.

Hogan, J. (1967). Fighting and reinforcement in the Siamese fighting fish (Betta splendens). J. Comp. Physiol. Psychol. 64, 356-359.

Krsiak, M., and Janku, I. (1969). The development of aggressive behavior in mice by isolation. In S. Garattini and E. B. Sigg (Eds.), "Aggressive Behavior." New York: Wiley.

Lagerspaetz, K., and Lagerspaetz, K. Y. H. (1971). Changes in the aggressiveness of mice resulting from selective breeding, learning and social isolation. Scand. J. Psychol. $12,241-248$.

Liem, K. F. (1963). "The Comparative Osteology and Phylogeny of the Anabantoidei (Teleostei, Pices)." Urbana: University of Illinois Press.

Melvin, K. B., and Anson, J. E. (1970). Image-induced aggressive display: Reinforcement in the paradise fish. Psychol. Rec. 20, 225-228.

Miller, R. J., and Miller, H. C. (1970). Studies on the agonistic behavior of anabantoid fishes. Proc. Okla. Acad. Sci. 49, 60-85.

Pal, B. C. (1968). Effect of length of isolation and degree of domestication on aggressive behavior in Indian paradisefish, Macropodus cupanus. Amer. Zool. 8, 750 (Abst).

Picciolo, A. R. (1964). Sexual and nest discrimination in anabantid fishes of the genera Colisa and Trichogaster. Ecol. Monogr. 34, 53-77.

Rasa, O. A. E. (1971). In Paul Parey (Ed.), "Appetence for Aggression in Juvenile Damsel Fish." Berlin:

Rozin, R., and Mayer, J. (1961). Regulation of food intake in the goldfish. Amer. J. Physiol. 201, 968-974.

Sevenster, P. (1968). Motivation and learning in sticklebacks. In D. Ingle (Ed.) "The Central Nervous System and Fish Behavior." Chicago: University of Chicago Press.

Simpson, M. J. A. (1968). The display of the Siamese fighting fish, Betta splendens. Anim. Behav. Monogr. 1, 1-73.

Southwick, C. H., and Ward, R. W. (1968). Aggressive display in the paradise fish, Macropodus opercularis L. Turtox News 46, 57-62.

Thompson, T. (1963). Visual reinforcement in Siamese fighting fish. Science 141, 55-57.

Thompson, T. (1969). Aggressive behavior of Siamese fighting fish-Analysis and synthesis of conditioned and unconditioned components. In S. Grattini and E. G. Sigg (Eds.), "Aggressive Behaviour." New York: Wiley.

Urich, R. (1966). Pain as a cause of aggression, Amer. Zool. 6, 643-662.

Valzelli, L. (1969). Aggressive behaviour induced by isolation. In S. Garattini and E. G. Sigg (Eds.), "Aggressive Behaviour." New York: Wiley.

Ward, R. W. (1967). Ethology of the paradisefish, Macropodus opercularis. I. Differences between domestic and wild fish. Copeia 4, 809-813. 